\title{
Diversidade genética de cultivares de alho avaliada por marcadores RAPD
}

\author{
Genetic diversity of garlic revealed by RAPD markers
}

Renato Luis VieiraI Rubens Onofre Nodari ${ }^{I}$

\section{RESUMO}

A variabilidade genética de genótipos de alho mantidos em Bancos de Germoplasma tem sido bastante investigada com marcadores morfológicos e bioquímicos; porém, as informações obtidas com esses marcadores têm sido consideradas inadequadas, devido ao pequeno número de marcadores disponíveis e a pequena porção genômica acessada, respectivamente. No Brasil, os conhecimentos atuais existentes sobre a diversidade genética do alho (Alium sativum L., $2 n=2 x=16)$ são resultantes de trabalhos realizados a partir de análise de características morfológicas e isoenzimas, relativamente pouco eficientes na deteç̧ão de polimorfismo. Com o objetivo de avaliar o grau de diversidade genética e identificar acessos duplicados através de análise de similaridade genética, foram avaliados, por meio de marcadores RAPD, 20 cultivares de alho que compõem o Banco de Germoplasma da Epagri. Foram produzidas 57 bandas, das quais 35 (61,42\%) revelaram polimorfismo. Os índices de similaridade revelados pelos marcadores RAPD foram geralmente altos para a maioria das cultivares da espécie A. sativum, sendo que algumas delas agruparam-se com $100 \%$ de similaridade, sugerindo serem cultivares potencialmente duplicadas, ou, pelo menos, que as diferenças genéticas entre si são mínimas.

Palavras-chave: Allium sativum, conservação, marcadores genéticos, polimorfismo.

\section{ABSTRACT}

Genetic variability of garlic genotypes maintained in Germplasm Banks has been investigated with morphologic and biochemical markers. However, the information gotten from these markers has been considered insufficient due to the small number of available markers and the small genomic portion accessed, respectively. In Brazil, the existing current knowledge on the genetic diversity of the garlic (Allium sativum L., $2 n=2 x=16$ ) is resultant mainly of studies carried out by morphologic and isozyme analysis, both considered relatively little efficient in polymorphism detection. With the objective to evaluate the degree of genetic diversity and to identify duplicate accessions by genetic similarity analysis, RAPD markers were used to evaluate 20 garlic cultivars maintained in the Bank of Germplasm of Epagri. A total of 57 RAPD bands have been produced, 35 of which $(61,4 \%)$ were polymorphic. The similarity indices disclosed by RAPD markers were generally high for the majority of the A. sativum cultivars. Some of them were grouped with $100 \%$ of similarity, probably being duplicated cultivars, or differing very little genetically.

Key words: Allium sativum, genetic markers, polymorphism.

\section{INTRODUÇÃO}

O alho tem sido descrito como uma espécie estéril ou como planta típica apomítica obrigatória, por isso sua propagação tem sido feita assexuadamente por meio de bulbilhos retirados da base da planta, ou por bulbilhos aéreos das inflorescências (POOLER \& SIMON, 1993). Uma das hipóteses correntes é a de que o alho provavelmente evoluiu de formas férteis para estéreis, e que clones férteis poderiam ainda sobreviver na área de origem da espécie (McCOLLUM, 1976). Portanto, a carência de reprodução sexual em alho e a falta de recombinação meiótica limitam a criação de recombinantes nessa espécie, sendo então a acumulação de mutações somáticas o material básico para a seleção. Assim, as possibilidades da aplicação de seleção sobre os genótipos já existentes são reduzidas e, portanto, o êxito dependerá muito da

'Empresa de Pesquisa Agropecuária e Extensão Rural de Santa Catarina S.A. (Epagri), Estação Experimental de Caçador, CP 591, 89500-000, Caçador, SC, Brasil. E-mail: revieira@epagri.rct-sc.br. Autor para correspondência.

"Programa de Pós-graduação em Recursos Genéticos Vegetais, Universidade Federal de Santa Catarina (UFSC), Florianópolis, SC, Brasil. E-mail: nodari@cca.ufsc.br. 
variabilidade genética existente em bancos de germoplasmas (BURBA, 1993).

Dos conhecimentos atuais existentes sobre a diversidade genética do alho no Brasil, a grande maioria são resultantes de trabalhos realizados a partir de análise de características morfológicas e utilizandose marcadores bioquímicos isoenzimáticos, relativamente pouco eficientes na detecção de polimorfismo. As informações sobre diversidade genética obtidas a partir desses marcadores, para a utilização em estratégias de conservação de germoplasma, têm sido consideradas insuficientes, devido ao pequeno número de marcadores disponíveis e a pequena porção genômica acessada, respectivamente. Por outro lado, os marcadores genéticos baseados na análise direta da molécula de DNA detectam alto nível de polimorfismo e permitem acesso a uma ampla região do genoma.

Com o desenvolvimento da técnica de PCR, foram desenvolvidos métodos que são baseados na amplificação do DNA genômico a partir de iniciadores que detectam polimorfismo específico de fragmentos de DNA. Dentre estes, os mais conhecidos e utilizados são RAPDs (Random Amplified Polymorphic DNA polimorfismo de DNA amplificado ao acaso) (WILLIAMS et al., 1990; WELSH \& MCCLELLAND, 1990) e AFLPs (Amplified Restriction Fragment Polymorphism - Polimorfismo de comprimento de fragmentos amplificados) (VOS et al., 1995).

Marcadores RAPD têm sido utilizados no melhoramento de plantas para identificar ao acaso regiões genômicas. Esses marcadores, de natureza dominante (MUELLER \& WOLFENBARGER, 1999), podem detectar rapidamente grande número de polimorfismo genético, por isso têm sido bastante utilizados para criação de mapas genéticos em um número significativo de espécies: Malus domestica (HEMMAT et al., 1997), Citrus (CRISTOFANI et al., 1999), Actinidia spp (TESTOLIN et al., 2001), Mangifera indica (KASHKUSH et al., 2001) e Prunus persica (CHAPARRO et al., 1993). Para alho, marcadores RAPD têm sido eficientes em alguns estudos de caracterização de bancos de germoplasmas (MAASS \& KLAAS, 1995; BRADLEY et al., 1996; Al-ZAHIM et al., 1997) e a sua utilização tem sido bastante atrativa por ser uma técnica bastante simplificada, de modesto custo, possibilitando gerar um grande número de marcadores em pouco tempo. Esta técnica também tem a vantagem, de, mesmo sem o conhecimento prévio do genoma, requerer pouca quantidade de DNA por análise (GOULÃO et al., 2001).

O objetivo deste trabalho foi avaliar, através de marcadores RAPD, o grau de diversidade genética existente entre os genótipos cultivados de alho que compõem o Banco Ativo de Germoplasma da Epagri e identificar acessos duplicados através de análise de similaridade genética.

\section{MATERIAL E MÉTODOS}

Um total de 20 cultivares, sendo dez delas introduzidas de outros países, foram amostradas no Banco Ativo de Germoplasma da Estação Experimental da Epagri, no município de Caçador (Tabela 1).

Extração de DNA - Folhas de plantas jovens, cultivadas a campo, foram utilizadas para extração de DNA, que foi realizada com base no protocolo proposto por VIEIRA (2002). Após a extração, o DNA foi quantificado em gel de agarose a $0,8 \%$, sendo em seguida estocado a $20^{\circ} \mathrm{C}$ negativos até o momento da análise RAPD.

Reações de amplificação - Sessenta iniciadores com 10 pares de bases (Operon Technologies) foram testados para identificação de marcadores polimórficos com bandas de forte intensidade passíveis de serem interpretadas com ausência de ambigüidade e com reproducibilidade. Após a seleção dos iniciadores, as seqüências de DNA das 20 amostras foram submetidas à reação de amplificação, de acordo com o protocolo descrito por

Tabela 1 - Identificação e procedência dos 20 genótipos de alho do Banco Ativo de Germoplasma da Epagri. Caçador, SC, 2004.

\begin{tabular}{llc}
\hline Nome da Cultivar & \multicolumn{1}{c}{ Espécie } & Procedência \\
\hline 1. Cará & A. sativum & Brasil \\
2. Gigante & A. sativum & Brasil \\
3. Chinesão & A. sativum & China \\
4. Chinês/Cl1 & A. sativum & China \\
5. Chinês/C12 & A. sativum & China \\
6. Soft Steim & A. sativum & China \\
7. Hard Steim & A. sativum & China \\
8. Russo & A. sativum & Rússia \\
9. Mexicano & A. sativum & México \\
10. Fuego - INTA & A. sativum & Argentina \\
11. Blanco & A. sativum & Argentina \\
12. Colorado & A. sativum & Argentina \\
13. Contestado & A. sativum & Brasil \\
14. Caçador 30 & A. sativum & Brasil \\
15. Caçador 40 & A. sativum & Brasil \\
16. Chonan & A. sativum & Brasil \\
17. Jonas & A. sativum & Brasil \\
18. Quitéria & A. sativum & Brasil \\
19. Caxiense & A. sativum & Brasil \\
20. Alho Rei & A. ampeloprasum & Brasil \\
\hline
\end{tabular}

Ciência Rural, v.37, n.1, jan-fev, 2007. 
FERREIRA\& GRATTAPAGLIA(1998), que consta de tampão PCR 1X, 2,5mM de $\mathrm{MgCl}_{2}, 0,2 \mathrm{mM}$ de dNTPs, $0,8 \mathrm{mg} \cdot \mu \mathrm{L}^{-1}$ de BSA, $0,4 \mu \mathrm{M}$ de iniciadores, $1 \mathrm{U}$ de enzima Taq DNA-polimerase e $13 \mu \mathrm{L}$ de volume total de reação. As reações de PCR foram realizadas em termociclador PTC-100 (MJ Research Inc.), constando da seguinte programação: $3 \mathrm{~min}$ a $95^{\circ} \mathrm{C}$ (desnaturação inicial do DNA), 45 ciclos de $1 \mathrm{~min}$ a $94^{\circ} \mathrm{C}$ (desnaturação), 1 min a $35^{\circ} \mathrm{C}$ (anelamento), $2 \mathrm{~min}$ a $72^{\circ} \mathrm{C}$ (extensão), com um passo final de extensão de 5 min a $72^{\circ} \mathrm{C}$ (AL-ZAHIM et al., 1997).

Os produtos de amplificação foram separados por eletroforese horizontal em gel de agarose $1,5 \%$, contendo $3 \mu \mathrm{L}$ de brometo de etídeo e submerso em tampão TBE $1 \mathrm{X}$ (tris-Cl 20mM, ácido bórico $2 \mathrm{mM} \mathrm{e}$ EDTA 20mM) sob corrente elétrica constante de 120 volts por $2 \mathrm{~h}$. Após a eletroforese, as bandas foram visualizadas sob luz ultra-violeta e fotodocumentadas. Para cada análise, um mesmo DNA foi desafiado duas vezes com reações de PCR idênticas, sendo consideradas somente as bandas reproduzidas nas duas reações.

Estimativa do Índice de Similaridade Genética - A partir dos padrões de banda das 20 amostras gerados pelos RAPDs, foi construída uma matriz binária, onde analisou-se a presença ou ausência de cada banda, codificada por " 1 " ou "0", respectivamente. Partindo-se dessa matriz, foi determinado o índice de similaridade de Jaccard entre todos os acessos, sendo posteriormente agrupados pelo método UPGMA (método das médias das distâncias; SNEATH \& SOKAL, 1973). A análise dos dados e a construção do dendograma foram feitas com auxílio do programa NTSYS-pc 2.02 (ROHLF, 1990).

\section{RESULTADOSE DISCUSSÃO}

Considerando que não existem relatos concretos sobre a verdadeira origem das cultivares de alho utilizadas no Brasil, torna-se difícil fazer inferências mais conclusivas a respeito da correlação entre a origem e os valores de similaridade genética encontrados entre os genótipos analisados neste trabalho, especialmente aqueles introduzidos de outros países. Entretanto, esta será a primeira contribuição no sentido de caracterizar e estimar a diversidade genética existente entre eles.

Dez iniciadores de seqüência arbitrária, selecionados para as análises RAPD, geraram um total de 57 bandas, das quais $35(61,4 \%)$ apresentaram polimorfismo, com média de 3,5 bandas polimórficas por iniciador (Tabela 2). Considerando que o presente trabalho buscou estimar a diverdidade genética entre indivíduos com sistema reprodutivo assexuado e, portanto, sem capacidade para recombinação genética, tal polimorfismo pode ser considerado alto se comparado com os relatados em alguns trabalhos utilizando marcadores RAPD: 3,0 para Araucária angustifólia (STEFENON, 2003); 1,8 para Pinus palustris (KUBISIAK et al., 1995) e 3,0 para Lycopersicon esculentum (RUS-KORTEKAAS et al., 1994). Entretanto, é baixo quando comparado com outras espécies: 4,2 para Eucalyptus urophylla (PIGATO \& LOPES, 2001); 5,0 para Picea abies (BUCCI \& MENOZZI, 1995) e 5,6 para Populus tremuloides (CHONG et al., 1994). Tal superioridade no grau de polimorfismo é compreensível, uma vez que estas espécies são férteis, predominando na sua maioria um sistema reprodutivo com fecundação cruzada, o que possibilita um maior nível de heterozigose nessas plantas.

Tabela 2 - Seqüência de nucleotídeos, número total de bandas, número de bandas polimórficas e porcentagem de bandas polimórficas para iniciadores RAPD utilizados para estimativa da diversidade genética dos genótipos de alho do Banco de Germoplasma da Epagri. Caçador, SC, 2004.

\begin{tabular}{lcccc}
\hline Iniciador & Seqüência de nucleotídeos & $\mathrm{N}^{\circ}$ total de bandas & $\mathrm{N}^{\text {o }}$ total de bandas polimórficas & $\begin{array}{c}\text { Porcentagem de bandas } \\
\text { polimórficas }\end{array}$ \\
\hline OPA-03 & AGTCAGCCAC & 4 & 2 & 50,0 \\
OPAN-05 & GGGTGCAGTT & 7 & 4 & 57,1 \\
OPB-17 & AGGGAACGAG & 3 & 3 & 100 \\
OPB-18 & CCACAGCAGT & 4 & 4 & 100 \\
OPC-07 & GTCCCGACGA & 7 & 5 & 71,4 \\
OPC-09 & CTCACCGTCC & 8 & 2 & 25,0 \\
OPD-10 & GGTCTACACC & 5 & 2 & 40,0 \\
OPE-06 & AAGACCCCTC & 9 & 5 & 55,5 \\
OPE-11 & GAGTCTCAGG & 6 & 5 & 83,3 \\
OPE-17 & CTACTGCCGT & 4 & 3 & 75,0 \\
Total & & 57 & 35 & \\
\hline
\end{tabular}

Ciência Rural, v.37, n.1, jan-fev, 2007. 
Como era de se esperar, por tratar-se de uma espécie diferente de $\boldsymbol{A}$. sativum, o alho "Rei", $\boldsymbol{A}$. ampelaprasum, posicionou-se isoladamente no dendograma (Figura 1). Além do padrão específico de bandas encontrado nesta espécie, o genótipo acessado apresenta características morfológicas, tanto da parte aérea quanto do bulbo, muito divergentes em relação aos acessos representantes da espécie A. sativum. Esse resultado corrobora os encontrados por SIQUEIRA et al., (1985) que detectaram padrões únicos de isoenzima para um clone da espécie $\boldsymbol{A}$. ampeloprasum.

Observando o dendograma obtido a partir das 57 bandas RAPD (correlação cofenética $=0,95$ ), observa-se a formação de outros dois grupos, com similaridade genética variando de 82 a $100 \%$. Nota-se que algumas cultivares apresentaram $100 \%$ de similaridade entre si, nos dois grupos, reforçando uma hipótese levantada sobre a existência de genótipos duplicados, com denominações diferentes em diferentes localidades nas lavouras de alho do Sul do Brasil (ALGUSTIN \& GARCIA, 1993). No grupo “A”, encontram-se as cultivares introduzidas no Brasil, exceto a cultivar "Chinesão", e está subdividido em três subgrupos: subgrupo A-1 ("Chinês/Cl1" e "Chinês/ Cl2"), com 100\% de similaridade interna; subgrupo A2 ("Fuego-INTA", "Caxiense" e "Colorado"), com similaridade interclonal de 100\%; e subgrupo A-3 ("Soft Steim", "Hard Steim" e "Russo"), também com similaridade interclonal de 100\%. Ainda, associadas a este subgrupo, estão as cultivares "Mexicano" e "Blanco" com $98 \%$ e $94 \%$ de similaridade com os dois subgrupos, respectivamente.

As cultivares de procedência chinesa "Chinês/C11" e "Chinês/Cl2" foram recentemente introduzidas no Brasil por agricultores da região produtora de Santa Catarina. Apresentam traços morfológicos idênticos das folhas, porém existem variações relacionadas à intensidade da cor roxa dos bulbilhos, possivelmente causadas por pressão de fatores ambientais. Apesar de terem compartilhado $100 \%$ dos marcadores utilizados, as cultivares de procedência argentina "Fuego-INTA" e "Colorado" diferem morfologicamente da cultivar "Caxiense", de origem brasileira, pela coloração da casca do bulbilho, tendo as cultivares argentinas bulbilhos com coloração roxa mais intensa. Cabe ressaltar que a cultivar "Caxiense" é plantada em diversas regiões do Sul do Brasil e recebe diferentes nomes, conforme a região de cultivo: "São Valentim", no Rio Grande do Sul, "Esmeralda" e "Caxiense", em Santa Catarina e no Paraná. É aceitável, portanto, considerar que os genótipos "Fuego-INTA" e "Colorado" estejam incluídos nestes cultivos recebendo as mesmas

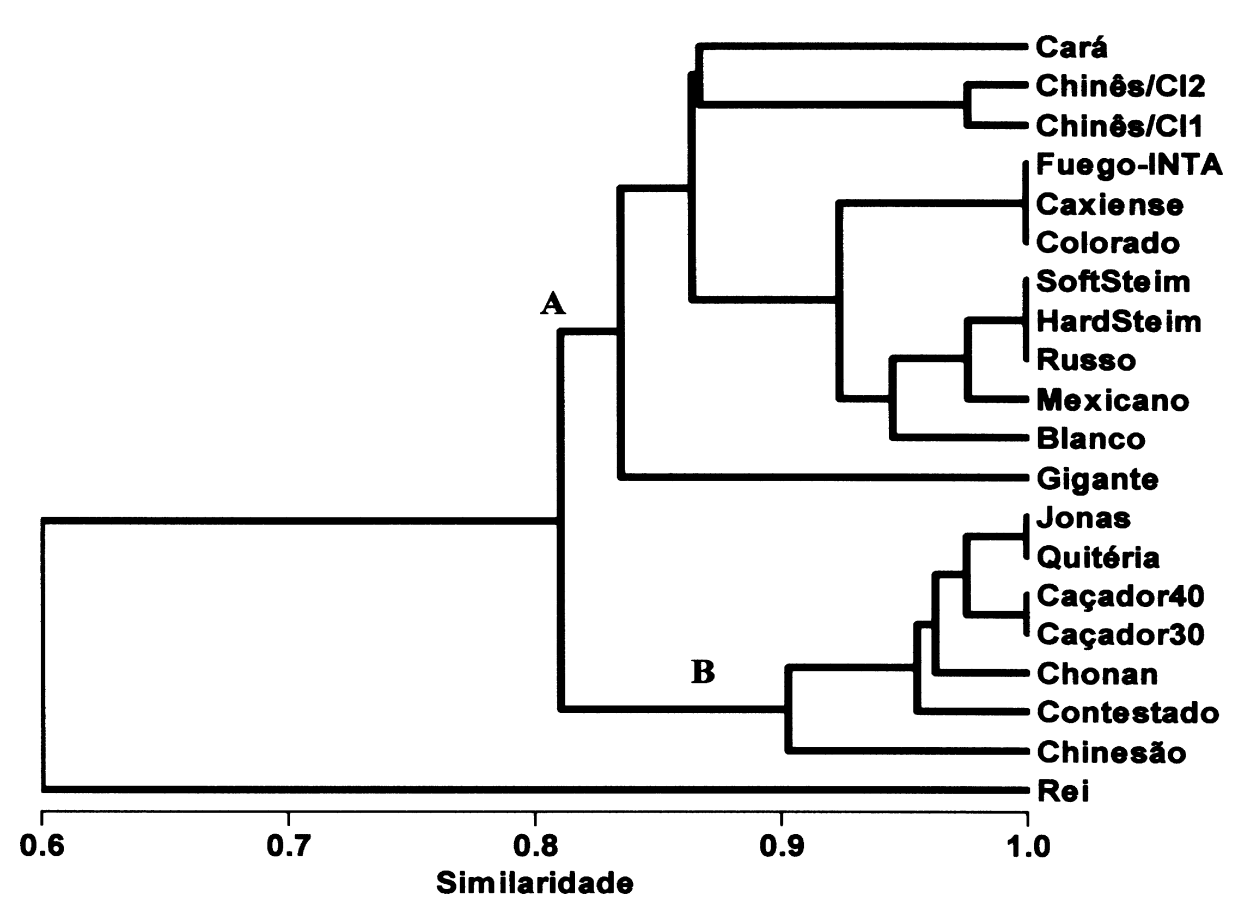

Figura 1 - Dendrograma de similaridade genética de 20 cultivares de alho, com base no Índice de Jaccard, estimado a partir de 57 marcadores RAPD $(r=0,95)$.

Ciência Rural, v.37, n.1, jan-fev, 2007. 
denominações, já que apresentam pequenas variações entre seus traços morfológicos.

As cultivares "Soft Steim" e "Hard Steim", também de procedência chinesa, juntamente com a cultivar "Russo", de procedência russa, apresentaram características idênticas em praticamente todos os traços morfológicos observados em ensaios de competição de cultivares realizados pela Epagri, exceto variações significativas encontradas no tamanho do bulbo da cultivar "Russo", levando a crer em uma possível mutação relacionada a esta característica.

Com relação às cultivares "Cará" e "Gigante", também situadas no grupo "A" e apresentando similaridade interna de $82 \%$, estas são, entre outras, cultivares selecionadas a partir de variedades "crioulas", coletadas em propriedades rurais do Sul do Brasil e mantidas em Bancos de Germoplasma. As variações morfológicas observadas entre essas duas cultivares dizem respeito, basicamente, ao aspecto foliar e ao formato do bulbo, tendo a primeira folhas verdes mais claras, estreitas e porte semi-ereto e o bulbo de formato achatado. A precocidade e a coloração clara dos bulbilhos são as principais características que essas duas cultivares apresentam em comum e tais características fazem com que sejam pertencentes ao grupo "comum" de cultivares, sendo de grande importância para as regiões de baixa altitude do Estado de Santa Catarina, por não apresentarem exigência de baixas temperaturas para cultivo (BIASI \& MUELLER, 1989).

No grupo "B", situam-se a maioria dos genótipos de procedência local, além da cultivar "Chinesão", de procedência chinesa, com similaridade de $90 \%$ com as demais cultivares desse grupo. Nota-se ausência de variação interclonal entre os pares de cultivares "Caçador-30" e "Caçador-40", "Quitéria" e "Jonas", discordando dos resultados obtidos no trabalho de VIEIRA (2004), no qual diferentes padrões de isoenzimas foram encontrados para estas mesmas cultivares, que apresentaram pouco mais de $80 \%$ de similaridade genética. As cultivares "Caçador-30" e "Caçador-40" são clones derivados da cultivar "Roxo Pérola de Caçador”. BIASI \& MUELLER (1989) constataram, através de ensaios de competição de cultivares, produtividades diferentes entre esses clones, o mesmo ocorrendo para as cultivares "Jonas" e "Quitéria". Ainda segundo VIEIRA (2004), utilizando análise multivariada para classificar um grupo de 96 acessos de alho, detectou diferenças nos traços morfológicos do bulbo dentro destes pares de cultivares. Todas as cultivares nacionais que compõem o grupo "B" também foram situadas em um mesmo grupo proposto por AUGUSTIN \& GARCIA (1993), para os padrões isoenzimáticos ACP, EST e PRX.

A cultivar "Contestado", que apresentou pouco mais de $95 \%$ de similaridade genética com as cultivares "Jonas" e "Quitéria", difere morfologicamente das últimas por apresentar folhas mais largas e decumbentes e ciclo mais precoce. Já a cultivar "Chonan" não apresenta praticamente nenhuma divergência nos traços morfológicos em relação às cultivares "Jonas", "Quitéria", "Caçador-30" e "Caçador-40"; no entanto, foi detectado nesta análise pouco mais de $95 \%$ de similaridade.

As descrições de cultivares de alho, em nível nacional, geralmente são incompletas e realizadas com distintos critérios, criando situações confusas quando se pretende realizar análise comparativa. $\mathrm{O}$ nível de especificidade de um genótipo, no manejo ao qual se submete, torna muito difícil fazer inferências de resultados, que podem ser equivocadas e de utilidade duvidosa para outros locais. Realmente, a variação entre cultivares de alho manifesta-se nos mais variados ambientes, podendo-se notar diferenças sensíveis no desenvolvimento da planta, no comprimento e na largura das folhas, no ciclo da cultura, na brotação prematura, na conformação, no tamanho e na cor do bulbo e, ainda, no número, no tamanho, na forma e na coloração dos bulbilhos. VIRK et al. (1995) sugeriram que uma decisão para que dois indivíduos sejam tomados como geneticamente idênticos só poderia ser feita através do uso das técnicas de discriminação mais eficientes disponíveis. Contudo, como caracteres morfológicos e marcadores à base de DNA acessam diferentes regiões do genoma, uma inferência sobre duplicata de acessos deve levar em conta um conjunto mínimo de informações. No presente trabalho, deve-se ponderar que as pequenas variações morfológicas manifestadas, principalmente entre as cultivares com inexistência de variação em nível molecular, podem ter sido causadas por poucas modificações no DNA, que causaram efeitos fenotípicos nas plantas, que foram captados pelos descritores morfológicos, mas não pelos moleculares, provavelmente pela baixa quantidade do genoma acessado. Além disso, a magnitude das diferenças entre os acessos de um modo geral também pode ter sido resultante da interação genótipo-ambiente.

\section{CONCLUSÕES}

Os índices de similaridade revelados pelos marcadores RAPD, foram geralmente altos para a maioria das cultivares da espécie A. sativum, sendo que algumas delas agruparam-se com $100 \%$ de similaridade, sugerindo que sejam cultivares 
potencialmente duplicadas ou que apresentem divergência mínima. Considerando-se tratar de uma espécie de propagação praticamente assexuada, os resultados encontrados nesta análise sugerem que existe uma quantidade razoável de diversidade genética entre os acessos do Banco de Germoplasma de alho da Epagri, demonstrando uma boa capacidade informativa dos marcadores RAPD para estimativa da diversidade genética em populações de alho, podendo, dessa forma, ser indicado para este tipo de estudo.

\section{AGRADECIMENTOS E APRESENTAÇÃO}

À Fundação Universidade do Contestado (UnC), pela concessão de bolsa de estudos ao primeiro autor. Trabalho extraído da Dissertação de mestrado apresentada pelo primeiro autor ao Programa de Pós-graduação em Recursos Genéticos Vegetais da Universidade Federal de Santa Catarina - UFSC, Florianópolis, SC, Brasil.

\section{REFERÊNCIAS}

AL-ZAHIM, M.H.J. et. al. Classification of genetic variation in garlic (Allium sativum L.) revealed by RAPD. HortScience, v.32, p.1102-1104, 1997.

AUGUSTIN, E.; GARCIA, A. Classificação isoenzimática, morfológica e agronômica de genótipos de alho. Horticultura Brasileira, v.11, n.1, p.10, 1993.

BIASI, J.; MUELLER, S. Comportamento de cultivares de alho no Planalto Catarinense. Horticultura Brasileira, Brasilia, v.7, n.1, p.7-9, 1989.

BRADLEY, K.F. et al. Classification of Australian garlic cultivars by DNA fingerprinting. Australian Journal of Agricultural Research, v.36, p.613-618, 1996.

BUCCI, G.; MENOZZI, P. Genetic variation of RAPD markers in a Picea abies Karst population. Heredity, v.75, p.188-197, 1995.

BURBA, J.L. Obtencion de nuevas variedades de ajo. 3.ed. Mendoza: INTA - EEA La Consulta, 1993. p.45-48.

CHAPARRO, J.X. et al. Target mapping and linkage analysis of morphological isozyme, and RAPD markers in peach. Theoretical and Applied Genetics, v.87, p.805-815, 1993.

CHONG, D.K.X. et al. Nucleotide divergence between populations of trembling aspen (Populus tremuloides) estimated with RAPDs. Current Genetics, v.8, p.374-376, 1994

CRISTOFANI, M. et al. Genetic linkage maps of Citrus sunki Hort. ex. Tan. and Poncirus trifoliata (L.) Raf. And mapping of citrus tristeza virus resistance gene. Euphytica, v.109, p.2532, 1999.

FERREIRA, M.E.; GRATTAPAGLIA, D. Introdução ao uso de marcadores moleculares em análise genética. 3.ed. Brasília: EMBRAPA-CENARGEN, 1998. p.145-154.
GOULÃO, L. et al. Comparing RAPD and AFLP analyis in discrimination and estimation of genetic similarities among apples (Malus domestica Borkh.) cultivars. Euphytica, v.119, p.259-270, 2001.

HEMMAT, M. et al. A DNA marker for columnar growth habit in apple contains a simple sequence repeat. Journal of the American Society for Horticultural Science, v.122, p.347349, 1997.

KASHKUSH, K. et al. Cultivar identification and genetic map of mango (Mangifera indica). Euphytica, v.122, p.129-136, 2001.

KUBISIAK, T.L. et al. RAPD linkage mapping in a longleaf pine x slash pine F1 family. Theorical and Applied Genetics, v.90, p.1119-1127, 1995.

McCOLLUM, G.D. Onion and allies. In: SIMMONDS, N.W. (Ed). Evolution of crop plants. New York: Longman, 1976. p.186-190.

MAASS, H.I.; KLAAS, M. Infraspecific differentiation of garlic (Allium sativum L.) by isozyme and RAPD markers. Theorical and Applied Genetics, v.91, p.89-97, 1995.

MUELLER, U.G.; WOLFENBARGER, L.L. AFLP genotyping and fingerprinting. Trees, v.14, n.10, p.389-394, 1999.

PIGATO, S.M.P.C.; LOPES, C.R. Caracterização silvicultural, botânica e avaliação da variabilidade genética por meio do marcador molecular RAPD em um teste de progênies de Eucaliptus urophylla S. T. Blake. Scientia Forestalis, v.60, n.3, p.135-148, 2001.

POOLER, M.R.; SIMON, P.W. Garlic flowering in response to clone, photoperiod, growth temperature, and cold storage. HortScience, v.28, n.1, p.1085-1086, 1993.

ROHLF, F.J. NTSYS-PC: numerical taxonomy and multivariate analysis. New York: Applied Biostatiscs, 1990. $139 \mathrm{p}$.

RUS-KORTEKAAS, W. et al. Direct comparison of levels of genetic variation in tomato detected by a GACA-containing microsatellite and by randon amplified polymorphic DNA. Genome, v.37, p.375-381, 1994.

SIQUEIRA, W.J. et al. Caracterização isoenzimática e morfológica de clones e introduções de alho. Bragantia, Campinas, v.44, n.1, p.357-374, 1985.

SNEATH, P.H.A; SOKAL, R.R. Numeral taxonomy. San Francisco: W.H. Freeman, 1973. 387p.

STEFENON, V.M. Adaptação e otimização de protocolos para a extração de DNA e para marcadores RAPD e AFLP e transferibilidade de iniciadores para marcadores microssatélites em Araucária angustifólia. 2003. 68f. Dissertação (Mestrado em Biotecnologia) - Universidade Federal de Santa Catarina. 
VIEIRA, R.L. Caracterização genética dos acessos do banco ativo de germoplasma de alho (Allium sativum $\mathrm{L}$.) de Santa Catarina. 2004. 92f. Dissertação (Mestrado em Recursos Genéticos Vegetais) - Universidade Federal de Santa Catarina.

TESTOLIN, R. et al. A kiwifruit (Actinidia spp.) linkage map based on microsatellites and integrated with AFLP markers Theoretical and Applied Genetics, v.203, p.30-36, 2001.

VIEIRA, E.A. Mapeamento genético da ameixeira (Prunus sp.) com base em uma população segregando para resistência a escaldadura das folhas (Xylella fastidiosa). 2002. 91f. Dissertação (Mestrado em Recursos Genéticos Vegetais) - Universidade Federal de Santa Catarina.
VIRK, P.S. et al. The identification of duplicate accessions within a rice germoplasm collection using RAPD analysis. Theorical and Applied Genetics, v.90, p.1049-1055, 1995.

VOS, P. et al. AFLP: a new technique for DNA fingerprinting. Nucleic Acids Research, local, v.23, n.1, p.4407-4414, 1995.

WELSH, J.; MCCLELLAND, M. Fingerprinting genomes using PCR with arbitrary primers. Nucleic Acids Research, v.18, p.7213-7218, 1990 .

WILLIANS, J.G.K. et al. DNA polymorphism amplified by arbitrary primers are useful as genetic markers. Nucleic Acids Research, v.18, p.6531-6535, 1990 